\section{La importancia de la emoción en el aprendizaje: \\ Propuestas para mejorar la motivación de los estudiantes}

Cuando vi el título de este artículo no tuve más remedio que leerlo con mucho detenimiento, dada su importancia en el proceso enseñanza-aprendizaje. Me alegró que Aránzazu Moreno, Ignacio Rodríguez y José Víctor Rodríguez, autores de este artículo, hayan tomado la decisión de escribir al respecto, apoyándose en la idea de que "todo aprendizaje tiene una base emocional”, enunciada hace 2000 años por Platón. Y qué bueno que estos profesionales vean la emoción y la cognición como dos armas poderosas en el proceso de adquisición de conocimientos.

Como maestro, estoy convencido de que la parte emocional y la cognitiva operan de forma interrelacionada en el cerebro del estudiante, permitiéndole predisponerse a un nuevo conocimiento. Están en lo cierto los autores de este artículo cuando recalcan la idea de que emoción y cognición están vinculadas a nivel biológico.

Este artículo es una herramienta que debe ser utilizada por los docentes que deseen convertir sus clases en algo atractivo, dada la importancia que tienen las emociones en el proceso enseñanza-aprendizaje. No contar con ellas significa estancarse.

Me solidarizo con los autores de este artículo respecto a la necesidad de eliminar los estados emocionales negativos en las aulas y cultivar los positivos. Los primeros arrastran consigo nefastas consecuencias en el proceso enseñanza-aprendizaje; mientras que los segundos aumentan la eficiencia del desarrollo del proceso cognitivo.

También me solidarizo con la idea de que la motivación es un elemento que está estrechamente vinculado con las emociones y que favorece el aprendizaje, ya que prepara física y mentalmente al estudiante, predisponiéndolo a la acción inducida. Por eso, considero que nuestro desafío consiste en encontrar cómo darle un propósito al aprendizaje y cómo estimular el impulso del deseo de aprender de los estudiantes.

Es impostergable incorporar en las aulas nuevas prácticas educativas en las que se fundan conocimiento y emoción. Esta fusión mejorará significativamente la motivación de los alumnos.

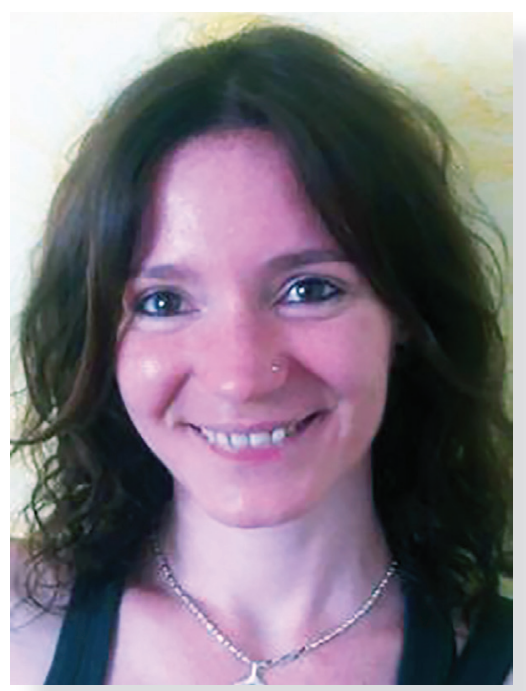

Aránzazu Elizondo Moreno

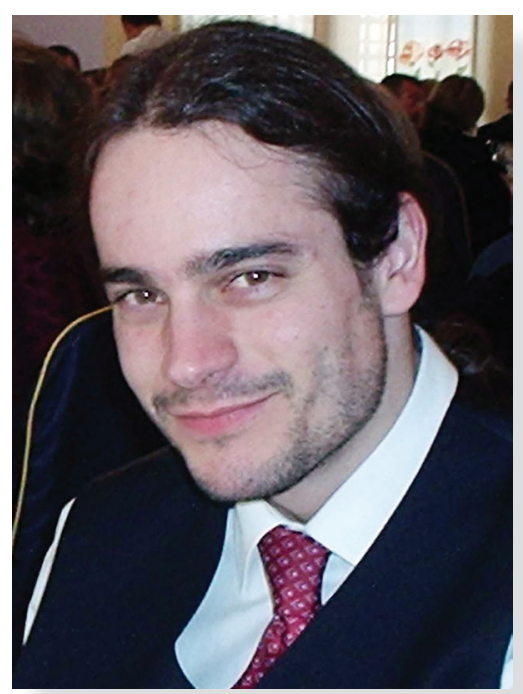

José Víctor Rodríguez Rodríguez

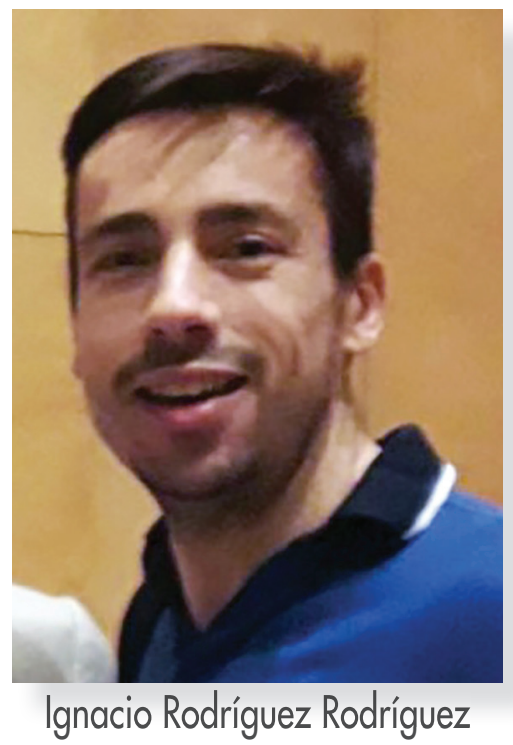


Comparto, cien por ciento, la lista de propuestas que los autores de este artículo presentan para estimular la motivación de los alumnos con el fin de mejorar la experiencia enseñanza-aprendizaje. Todo docente que desee convertir su clase en un lugar apropiado y motivador debe analizar en serio esta lista, profundizar en ella y ponerla en práctica. A mí, como docente, me ha ayudado extraordinariamente, específicamente las siguientes propuestas:

- Aprovecha la expectación del primer día.

El primer contacto con los estudiantes es el punto de partida para el éxito, ya que genera expectativa, estimula el interés hacia la asignatura e ilusiona.

- Comience a conocer a sus estudiantes.

Los alumnos necesitan sentir que su profesor se preocupa por ellos.

- Trasládeles la importancia de su asignatura.

Los alumnos necesitan saber por qué deberían aprender la materia que imparte para poder motivarse e implicarse en ella.

- Entusiásmese.

Los alumnos se motivan si perciben que a usted también le apasiona lo que imparte.

- Varíe constantemente su metodología de enseñanza.

Convierta su clase en una experiencia enriquecedora, sorpresiva y variada, ya que la rutina puede ser el comienzo de la desmotivación.

- Estimule la participación activa de los alumnos.

Haga preguntas sugerentes y anime a que se genere un clima participativo y de protagonismo por parte de los estudiantes.

- Proporcione que el estudiante descubra por sí mismo el conocimiento.
Plantee retos en forma de resolución de problemas, casos prácticos o proyectos individuales o grupales.

- Utilice el humor.

A través de este recurso puede generarse una atmósfera distendida que motive y favorezca el aprendizaje.

- Enriquezca su clase con todo tipo de recursos.

Más allá de los contenidos del programa, utilice otros recursos que los enriquezcan y complementen.

- Termine las clases con interrogantes que estimulen la curiosidad.

Esto ayudará a que los alumnos acudan expectantes a la siguiente clase.

Prof. Juan Féliz Alcántara Departamento de Humanidades 